\title{
UM ESTUDO SOBRE CLIMA ORGANIZACIONAL NO AMBIENTE HOSPITALAR
}

\author{
VIGNERON, D. M. S., GOMES, D. R., CASTRO, L. N. P.O.; REIS, T. B. \\ Institutos Superiores de Ensino do CENSA - ISECENSA, Rua Salvador Correa, 139, Centro, \\ Campos dos Goytacazes, RJ, Brasil
}

Toda organização é composta por recursos materiais e por capital humano, e ambos estão intimamente ligados. Para melhor aproveitamento dos colaboradores, torna-se imprescindível ter em mente os conceitos de gestão de pessoas, sabendo-se que colaboradores satisfeitos são mais produtivos e levam à empresa ao sucesso. Segundo Bispo (2006) a pesquisa de clima organizacional é a mais objetiva e segura dentre todas as diversas ferramentas que são criadas constantemente para avaliar o nível de relacionamento entre empresas e colaboradores, podendo identificar problemas reais na gestão de Recursos Humanos. Este estudo tem por objetivo geral avaliar o Clima Organizacional em um Hospital Público do município de Campos dos Goytacazes, RJ. De forma específica, além de realizar um diagnóstico do grau de motivação dos colaboradores dentro do hospital através de uma pesquisa de Clima Organizacional, busca-se também conhecer o comportamento dos entrevistados em relação às variáveis que interferem no clima. Portanto este estudo apresenta-se a seguinte problemática: Quais os fatores que influenciam no Clima Organizacional do Hospital Público X? Para desenvolver este trabalho foi realizada uma pesquisa do tipo exploratória por meio do levantamento bibliográfico e estudo de caso que proporcionou maior familiaridade com o problema e com o objetivo proposto. A pesquisa foi aplicada na emergência de um hospital público na cidade de Campos dos Goytacazes - RJ, referência em atendimentos de emergência. O questionário para avaliação do Clima Organizacional foi adaptado de Santos et al. (2012) e dividido em duas partes. A primeira parte com perguntas referentes ao perfil dos respondentes e a segunda com perguntas relacionadas ao trabalho. Foram avaliados 42 colaboradores da emergência, com idade entre 18 e 60 anos, de ambos os sexos. Quanto ao perfil dos colaboradores constatou que a maioria tem entre 06 e 18 anos de empresa, revelando uma baixa rotatividade. Dentre os colaboradores entrevistados, $64 \%$ eram do sexo feminino e apenas $36 \%$ do sexo masculino. A maior parte dos colaboradores entrevistados possui mais de 32 anos, sendo que 57\% possui Ensino Médio completo, revelando pouca especialização. Na segunda parte do questionário foi avalia a opinião dos colaboradores em relação a: vida profissional, relacionamento interpessoal, treinamento e desenvolvimento, ambiente de trabalho, estilo de liderança, remuneração e comunicação. A partir do questionário aplicado, chegou-se a conclusão de que as respostas com índices mais baixos de satisfação por parte dos colaboradores fazem referência a Treinamento e Desenvolvimento, Ambiente de Trabalho, Remuneração e Comunicação. Bispo (2006) afirma que o clima favorável é capaz de beneficiar clientes, 
organização e colaboradores, assim como um clima desfavorável pode prejudicar a todos. Com relação à Treinamento e Desenvolvimento, notou-se uma carência, mostrando que mais de $90 \%$ os entrevistados informam não receber treinamentos nem incentivo para se aperfeiçoar. $\mathrm{O}$ aperfeiçoamento acaba sendo crucial, pois como afirmam Borba e Kliemman Neto (2008), o atendimento primário dado ao paciente é um elemento de extrema relevância para a melhora na qualidade no atendimento. No hospital pesquisado, apesar dos cargos serem de certa forma estáveis, o fato da remuneração ser fixa e não muito elevada causa desconforto. Além disso, o Ambiente de Trabalho apresenta mais da metade dos colaboradores está insatisfeito. A comunicação também demonstrou ser um ponto a ser verificado, pois mais $60 \%$ dos entrevistados dizem não ser ouvidos e não participar das decisões, o que influencia diretamente na forma de executar as tarefas planejadas pelos superiores. De modo geral, os colaboradores demonstram estar insatisfeitos com o hospital, especialmente com a falta de incentivo ao crescimento e falta de comunicação e com o ambiente de trabalho não favorável. Quanto aos demais aspectos, como relacionamento entre as equipes e com superiores há pontos menos relevantes e a maior parte dos entrevistados demonstra estar satisfeita. Tais fatores são também cruciais para manter a qualidade do atendimento e sempre devem ser avaliados e mantidos em bons níveis.

Palavras-chaves: clima organizacional, gestão hospitalar, organização.

\section{REFERÊNCIAS}

BISPO, C. A. F. Um novo modelo de pesquisa de clima organizacional. Prod. [online]. 2006, vol.16, n.2, pp. 258-273. ISSN 0103-6513. Disponível em: < http://www.scielo.br/pdf/prod/v16n2/06.pdf> Acesso em 10 Set. 2014.

BORBA, G. S. de; KLIEMANN NETO, F. J. Gestão Hospitalar: identificação das práticas de aprendizagem existentes em hospitais. Saúde soc. [online]. 2008, vol.17, n.1, pp. 44-60. ISSN 19840470. Disponível em: <http://www.scielo.br/scielo.php?script=sci_arttext\&pid=S0104-12902008000100005 >. Acesso em 06 Maio. 2015.

SANTOS, B. S.; WiltenburG, T. D.; COLMENERO, J. C.; SOARES, A. L. Pesquisa De Clima Organizacional: Um Estudo Com Os Colaboradores De Um Hospital Universitário. XXXII ENCONTRO NACIONAL DE ENGENHARIA DE PRODUCAO Desenvolvimento Sustentável e Responsabilidade Social: As Contribuições da Engenharia de Produção. Bento Gonçalves, RS, Brasil, 2012. 